Nota / Note

\title{
ATRAÇÃO E DESENVOLVIMENTO DE Leptoglossus gonagra (Fabr.) (Hemiptera: Coreidae) EM CULTIVARES DE ABÓBORA E MORANGA
}

\author{
Edson Luiz Lopes Baldin ${ }^{1,3 *}$; Antonio Cesar Caetano ${ }^{2,4}$; Fernando Mesquita Lara ${ }^{2,5}$ \\ ${ }^{1}$ Depto. de Biologia / Bloco R - USP/FFCLRP, Av. Bandeirantes, 3900 - CEP: 14040-901 - Ribeirão Preto, SP. \\ ${ }^{2}$ Depto. de Fitossanidade - UNESP/FCAV, Via de Acesso Paulo D. Castellane s/ $n^{\circ}$ - CEP: 14870-000 - Jaboticabal, \\ $S P$. \\ ${ }^{3}$ Bolsista FAPESP. \\ ${ }^{4}$ Bolsista CAPES. \\ ${ }^{5}$ Bolsista CNPq \\ *Autor correspondente <elbaldin@usp.br>
}

\begin{abstract}
RESUMO: As plantas da família Cucurbitaceae são seriamente prejudicadas pelo ataque de insetos, sendo que os danos ocorrem desde a germinação até a colheita e podem ser observados em todas as partes da planta. Dentre os insetos sugadores que atacam a abóbora (Cucurbita moschata) e a moranga (C. maxima), as formas jovens e adultas do percevejo Leptoglossus gonagra (Fabr.) (Hemiptera: Coreidae) merecem destaque por sugarem a seiva das folhas, ramos e frutos novos, nos quais causam necroses, reduzindo a produção. Visando comparar a atratividade de plântulas de cultivares de abóbora e moranga a adultos deste percevejo e os efeitos desses materiais sobre a biologia de ninfas dessa espécie, realizaram-se ensaios sob condições de laboratório. Em teste de atratividade, o cultivar de abóbora BRA015113 destacou-se como o menos atrativo em relação ao cultivar de moranga Exposição, enquanto que o cultivar de abóbora BRA003531 foi o mais atrativo. Todos os cultivares provocaram $100 \%$ de mortalidade das ninfas, indicando a presença de componentes antibióticos, adversos ao desenvolvimento de L. gonagra.

Palavras-chave: Insecta, resistência de plantas, plântulas, atratividade, antibiose
\end{abstract}

\section{ATTRACTION AND DEVELOPMENT OF Leptoglossus gonagra (Fabr.) (Hemiptera: Coreidae) IN SQUASH AND PUMPKIN CULTIVARS}

\begin{abstract}
Cucurbitaceae plants are seriously damaged by attack of insects and the damages are present from germination to harvest, in all parts of the plants. Among sucking insects attacking squash (Cucurbita moschata) and pumpkin (C. maxima), the nymphs and adults of Leptoglossus gonagra (Fabr.) (Hemiptera: Coreidae) are pointed as one of the main pests, sucking leaves, branches and fruits, causing necrosis and reducing the yield. To compare the attractivity of seedlings of squash and pumpkin cultivars in respect to adults of this insect, and the effects of these plants on the biology of the nymphs, assays were carried out under laboratory conditions. For the attractivity test, the BRA015113 squash genotype was the least attractive as compared to the Exposição pumpkin genotype, while BRA003531 was preferred. All the genotypes caused $100 \%$ of mortality of the nymphs, indicating the presence of antibiotic components, harmful to the biological development of $L$. gonagra.
\end{abstract}

Key words: Insect, host plant resistance, seedlings, attractivity, antibiosis

\section{INTRODUÇÃO}

A família Cucurbitaceae engloba mais de 800 espécies de plantas, agrupadas em cerca de 80 gêneros, das quais muitas têm grande importância econômica na horticultura mundial. Segundo Lopes (1991) a produção brasileira de cucurbitáceas vem crescendo cerca de $10 \%$ ao ano a partir de 1988, destacando-se a abóbora, abobrinha, chuchu, melão, melancia, moranga e pepino como as espécies mais expressivas na economia agrícola nacional. Os índices apresentados pela FAO (1999) registraram 843 mil toneladas de frutos produzidos na América do Sul. No Brasil, cerca de 17 mil toneladas de frutos foram comercializadas na
Ceagesp-SP durante o ano de 1996 (FNP Consultoria e Comércio, 1998).

Dentre as muitas pragas que atacam as cucurbitáceas em todo o mundo, o percevejo Leptoglossus gonagra Fabr. merece destaque pela elevada versatilidade de plantas hospedeiras (Brailovsky \& Sánches, 1982). No Brasil este inseto é conhecido como percevejo do melão-de-São-Caetano, podendo também atacar a abóbora, algodoeiro, araçazeiro, bucha, chuchu, pepino, melancia, girassol, goiabeira, mamoneira, mangueira, maracujá, romã e citros (Silva et al., 1968; Brailovsky \& Sánches, 1982; Gallo et al., 1988; Boaretto, et al., 1994; Ruggiero et al. 1996; Boiça Júnior, 1998). 
$\mathrm{O}$ adulto de $L$. gonagra é descrito como um percevejo de coloração geral marrom escura, com cerca de $2 \mathrm{~cm}$ de comprimento; as pernas posteriores são mais largas, apresentando tíbia provida de expansões laterais; apresenta ainda listras alaranjadas na cabeça (Gallo et al., 1988). Quanto aos danos provocados nas cucurbitáceas, este inseto, tanto na forma adulta como na forma jovem, ataca as folhas, os ramos e os frutos ainda novos, sugando-lhes a seiva e podendo causar necroses secundárias. Como consequência, as plantas ficam depauperadas e os frutos podem empedrar-se na região atacada. Ao se alimentarem das plantas, os insetos também injetam toxinas, prejudicando ainda mais o seu desenvolvimento (Brailovsky \& Sánches, 1982; Gallo et al., 1988).

O controle químico é o método mais utilizado contra o percevejo $L$. gonagra, entretanto, outras táticas não prejudiciais ao meio ambiente e ao homem, como a rotação de culturas, o controle biológico e o uso de materiais resistentes vêm crescendo em importância. Segundo Rossetto et al. (1981) e Lara (1991), este último método vem se destacando como um dos mais desejáveis em função do baixo custo e por dispensar a necessidade de conhecimentos prévios do agricultor.

Em função da necessidade do desenvolvimento de métodos alternativos de controle do percevejo $L$. gonagra, realizou-se este trabalho, visando selecionar plântulas de cultivares de abóbora Cucurbita moschata Duch. menos atrativas a adultos do inseto em comparação com um cultivar de moranga (C. maxima Duch.), além de se observar alguns aspectos biológicos de ninfas confinadas sobre estes materiais.

\section{MATERIAL E MÉTODOS}

O trabalho foi realizado sob condições controladas no Laboratório de Resistência de Plantas a Insetos do Departamento de Fitossanidade, pertencente à Faculdade de Ciências Agrárias e Veterinárias, UNESP, Jaboticabal, durante o ano de 1999.

Criação do Inseto - Durante a realização dos estudos, foi mantida uma criação de $L$. gonagra sob condições controladas $\left(25 \pm 2^{\circ} \mathrm{C}, 65 \pm 10 \%\right.$ UR e Fotofase de 12 h) em gaiolas de vidro com dimensões de $30 \times 30 \mathrm{~cm}$ de base por $40 \mathrm{~cm}$ de altura e $0,4 \mathrm{~cm}$ de espessura. Para o início da criação, percevejos adultos foram coletados em pomar de maracujazeiro da UNESP/Jaboticabal, sendo trazidos para o laboratório. Os insetos foram colocados no interior das gaiolas, sendo alimentados com frutos, ramos e botões florais de maracujazeiro, a fim de evitar o condicionamento pré-imaginal, citado por Lara (1991).

Ensaio de Atratividade - No interior de gaiolas teladas $(1,5 \times 0,50 \times 0,50 \mathrm{~m})$ realizou-se um teste de atratividade com adultos de $L$. gonagra, utilizando-se plântulas de 1520 dias de idade de 33 cultivares de abóbora $C$. moschata (BRA003531, BRA003433, BRA014737, BRA015156, BRA015008, BRA013714, BRA014958, BRA014923, BRA014893, BRA003662, BRA015105, BRA003671, BRA015032, BRA014711, BRA014702, BRA015016, BRA014991, BRA015113, BRA014940, BRA014669, BRA003638, BRA014672, BRA014770, BRA003603, BRA014681, BRA014788, BRA015024, BRA014869, BRA015059, BRA014915, BRA014664, BRA014745, BRA014834) e um cultivar comercial de moranga C. maxima (Exposição), utilizado como cultivar padrão no cálculo do índice de atratividade. Os insetos utilizados no ensaio foram retirados das gaiolas de criação e mantidos sob jejum por 24 horas antes do início do teste. Liberou-se então uma proporção de 5 indivíduos/cultivar, avaliando-se o número de insetos atraídos por material a 45, 60 e 90 minutos da liberação, em 4 repetições, seguindo um delineamento experimental inteiramente casualizado. Devido ao grande número de materiais em estudo, foi necessário utilizar três das gaiolas já mencionadas acima para cada repetição, colocando-se, ao acaso, dentro de cada uma delas 11 cultivares de abóbora, juntamente com o cultivar de moranga (presente nas três). Utilizando-se uma adaptação da fórmula citada por Lin et al. (1990) para índice de consumo, calculou-se o índice de atratividade do inseto $[I A=2 G /(G+P)]$, onde $I A=$ índice de atratividade; $G=$ número de insetos atraídos para 0 cultivar avaliado e $\mathrm{P}=$ número de insetos atraídos para o cultivar padrão (Exposição). Os valores de IA variam entre 0 e 2, com $I A=1$ indicando atração semelhante entre o cultivar avaliado e o padrão, $I A>1$ indicando maior atração pelo cultivar avaliado e, $I A<1$, indicando menor atração pelo cultivar avaliado. Os materiais foram classificados comparando-se o índice obtido no cultivar avaliado com o do cultivar padrão, adotando-se o erro padrão da média obtido na análise de cada período, para diferenciação dos mesmos. Em função dos índices de atratividade e da disponibilidade de sementes, selecionaram-se 11 cultivares, incluindo-se o de moranga (Exposição) para o estudo de alguns aspectos biológicos das ninfas de L. gonagra.

Desenvolvimento Biológico de Ninfas - Para avaliar a biologia das ninfas de L. gonagra nos diferentes cultivares de abóbora, utilizaram-se 11 gaiolas de vidro com as dimensões já descritas, colocando-se em seu interior uma plântula (15 - 20 dias de idade), semeada em substrato adequado, dentro de copo plástico de $300 \mathrm{~mL}$. A partir das gaiolas de criação, 50 ovos de diferentes idades foram coletados ao acaso, sendo colocados dentro de uma pequena placa de plástico junto ao colo das plantas, a fim de facilitar o deslocamento das ninfas até o hospedeiro.

Após a colocação dos ovos nas gaiolas, iniciaram-se as avaliações diárias, sempre no período da manhã, observando-se o desenvolvimento de cada inseto, conforme a metodologia descrita por Baldin \& Boiça Jr. (1999). Os ovos não viáveis colocados nas 
repartições foram devidamente trocados conforme a necessidade. Cada inseto representou uma repetição (50/cultivar), empregando-se um delineamento inteiramente casualizado. Para a manutenção dos ensaios, os restos de ovos, exúvias e insetos mortos, foram retirados diariamente, através de um bastão de madeira, com a ponta envolvida em algodão umedecido.

Avaliou-se a duração de cada ínstar ninfal (N1, N2), a mortalidade nos diferentes ínstares ninfais e a mortalidade total na fase imatura. $\mathrm{O}$ acompanhamento do terceiro ínstar ninfal (N3) foi feito somente no cultivar BRA003531, já que as ninfas submetidas aos outros cultivares não chegaram a atingir esta fase de desenvolvimento.

Os dados referentes ao período de duração/ ínstar foram submetidos a análise de variância através do teste $F$, sendo suas médias transformadas em $(x+0,5)^{1 / 2}$ e comparadas pelo teste de Tukey a $5 \%$.

\section{RESULTADOS E DISCUSSÃO}

Ensaio de Atratividade - Os maiores índices de atratividade foram observados no cultivar BRA003531, superando os do padrão (Exposição) e destacando-se como o material mais atrativo durante os três períodos de observação. Os cultivares BRA014923, BRA015024 e BRA014893, apesar de apresentarem índices acima de 1,00 em alguns dos períodos, apresentaram atratividade semelhante ao cultivar Exposição, sendo classificados como neutros. BRA015113, BRA013714, BRA014770 e BRA014788 apresentaram os menores índices de atratividade, com valores iguais a zero em pelo menos um dos períodos de avaliação, revelando serem os menos atrativos ou mais repelentes em relação ao padrão (Tabela 1). O cultivar BRA003531 confirmou ser o mais atrativo, apresentando o maior número acumulado de insetos durante as avaliações, com valor próximo a 45 insetos, enquanto que nenhum dos demais materiais atraiu mais que 30 insetos; BRA015113 revelou-se como o menos atrativo ou mais repelente, não atraindo nenhum inseto para suas plântulas durante os três períodos de observação (Figura 1).

De acordo com o comportamento apresentado pelos insetos em relação aos cultivares (Figura 1) e também em função da maior disponibilidade de sementes de alguns materiais, optou-se por selecionar 11 materiais para o estudo de alguns parâmetros biológicos das ninfas de L. gonagra, sendo 7 menos atrativos ou mais repelentes em relação ao padrão (BRA014711, BRA014869, BRA014737, BRA014664, BRA014770, BRA014788 e BRA015113), 2 com atratividade semelhante ao padrão (BRA003603 e BRA015024), 1 mais atrativo que o padrão (BRA003531) e o próprio padrão (Exposição).

Desenvolvimento Biológico de Ninfas - A duração média do primeiro ínstar ninfal (N1) foi maior quando as ninfas foram confinadas no cultivar BRA014711 (Tabela 2), seguido por BRA014869, BRA014737, BRA014664 e BRA014770 e diferindo estatisticamente $(p \leq 0,05)$ dos demais cultivares. O cultivar BRA003531 propiciou o menor período de duração para este ínstar, diferindo significativamente de todos os outros materiais. Baixos ou nenhum índice de mortalidade foram apresentados pela maioria dos cultivares no primeiro ínstar, exceto por

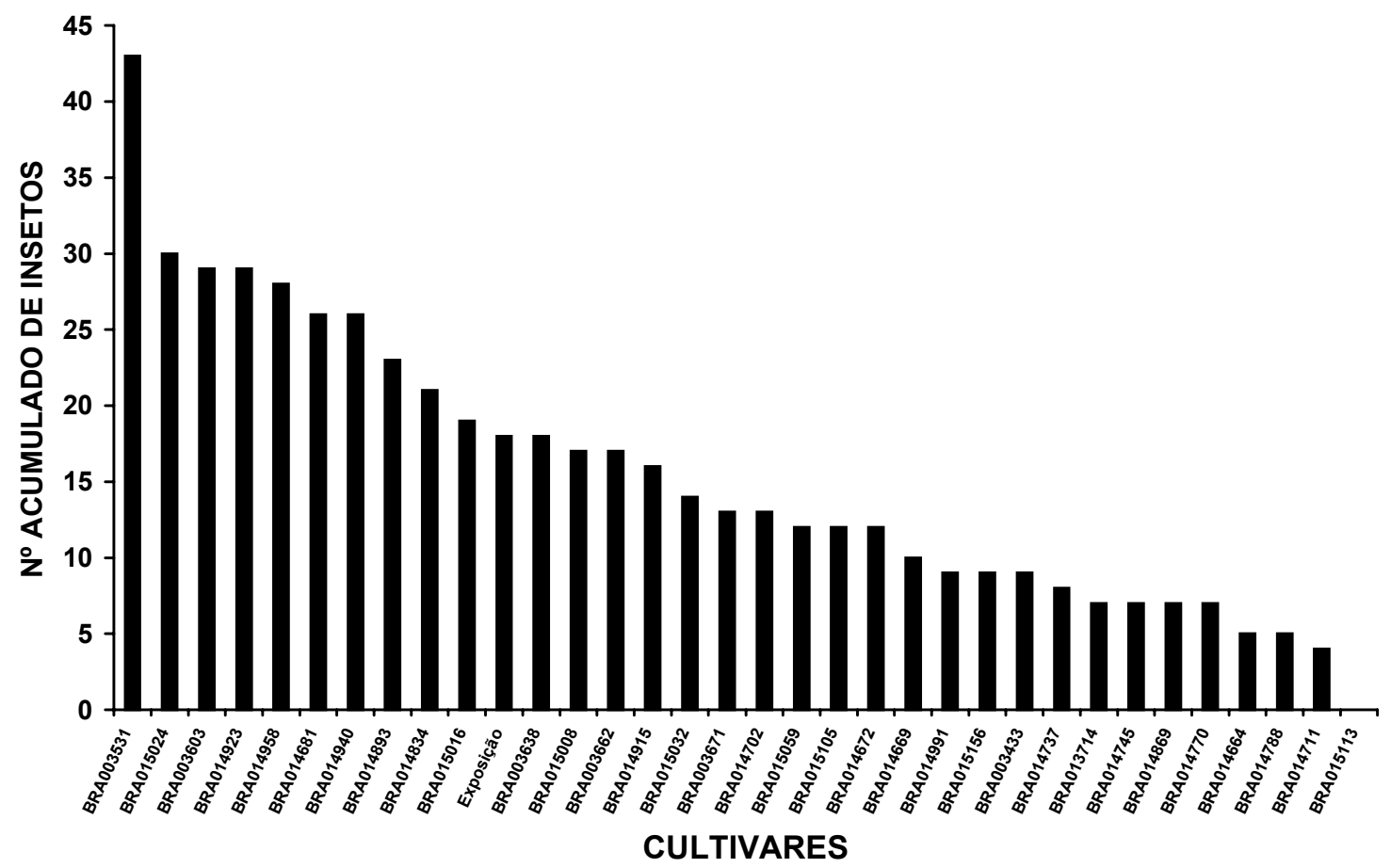

Figura 1 - Número acumulado (45, 60 e 90 min.) de adultos de Leptoglossus gonagra atraídos para plântulas de diferentes cultivares de abóbora. 
Tabela 1 - Índice de atratividade $(\mathrm{M} \pm \mathrm{EP})$ e classificação de plântulas de diferentes cultivares de abóbora quanto à atração de L. gonagra em quatro períodos de observação.

\begin{tabular}{|c|c|c|c|c|c|c|}
\hline \multirow{2}{*}{ Cultivar } & \multicolumn{2}{|c|}{45 minutos } & \multicolumn{2}{|c|}{60 minutos } & \multicolumn{2}{|c|}{90 minutos } \\
\hline & $\mathrm{M}( \pm \mathrm{EP})^{1}$ & Classif ${ }^{2}$ & $\mathrm{M}( \pm \mathrm{EP})^{1}$ & Classif. ${ }^{2}$ & $\mathrm{M}( \pm \mathrm{EP})^{1}$ & Classif.2 \\
\hline BRA003531 & $1,42 \pm 0,18$ & + & $1,28 \pm 0,14$ & + & $1,27 \pm 0,14$ & + \\
\hline BRA014923 & $1,15 \pm 0,18$ & $\mathrm{~N}$ & $1,04 \pm 0,14$ & $\mathrm{~N}$ & $0,94 \pm 0,14$ & $\mathrm{~N}$ \\
\hline BRA015024 & $1,13 \pm 0,18$ & $\mathrm{~N}$ & $0,92 \pm 0,14$ & $\mathrm{~N}$ & $0,88 \pm 0,14$ & $\mathrm{~N}$ \\
\hline BRA014893 & $1,12 \pm 0,18$ & $\mathrm{~N}$ & $0,95 \pm 0,14$ & $\mathrm{~N}$ & $0,88 \pm 0,14$ & $\mathrm{~N}$ \\
\hline Exposição & $1,00 \pm 0,18$ & $P$ & $1,00 \pm 0,14$ & $\mathrm{P}$ & $1,00 \pm 0,14$ & $P$ \\
\hline BRA014681 & $0,98 \pm 0,18$ & $\mathrm{~N}$ & $0,82 \pm 0,14$ & - & $1,01 \pm 0,14$ & $N$ \\
\hline BRA003662 & $0,96 \pm 0,18$ & $\mathrm{~N}$ & $0,87 \pm 0,14$ & $\mathrm{~N}$ & $0,83 \pm 0,14$ & - \\
\hline BRA014702 & $0,92 \pm 0,18$ & $\mathrm{~N}$ & $0,75 \pm 0,14$ & - & $0,54 \pm 0,14$ & - \\
\hline BRA014940 & $0,88 \pm 0,18$ & $\mathrm{~N}$ & $0,67 \pm 0,14$ & - & $0,95 \pm 0,14$ & $\mathrm{~N}$ \\
\hline BRA014672 & $0,88 \pm 0,18$ & $\mathrm{~N}$ & $0,71 \pm 0,14$ & - & $0,67 \pm 0,14$ & - \\
\hline BRA014834 & $0,86 \pm 0,18$ & $\mathrm{~N}$ & $0,76 \pm 0,14$ & - & $0,58 \pm 0,14$ & - \\
\hline BRA014958 & $0,83 \pm 0,18$ & $\mathrm{~N}$ & $0,78 \pm 0,14$ & - & $0,69 \pm 0,14$ & - \\
\hline BRA015016 & $0,79 \pm 0,18$ & - & $0,70 \pm 0,14$ & - & $0,73 \pm 0,14$ & - \\
\hline BRA015008 & $0,78 \pm 0,18$ & - & $0,74 \pm 0,14$ & - & $0,74 \pm 0,14$ & - \\
\hline BRA014915 & $0,71 \pm 0,18$ & - & $0,83 \pm 0,14$ & - & $0,79 \pm 0,14$ & - \\
\hline BRA015105 & $0,63 \pm 0,18$ & - & $0,72 \pm 0,14$ & - & $0,62 \pm 0,14$ & - \\
\hline BRA003671 & $0,63 \pm 0,18$ & - & $0,70 \pm 0,14$ & - & $0,75 \pm 0,14$ & - \\
\hline BRA003603 & $0,62 \pm 0,18$ & - & $0,91 \pm 0,14$ & $\mathrm{~N}$ & $0,91 \pm 0,14$ & $\mathrm{~N}$ \\
\hline BRA015059 & $0,58 \pm 0,18$ & - & $0,67 \pm 0,14$ & - & $0,67 \pm 0,14$ & - \\
\hline BRA003638 & $0,54 \pm 0,18$ & - & $0,54 \pm 0,14$ & - & $0,56 \pm 0,14$ & - \\
\hline BRA015032 & $0,53 \pm 0,18$ & - & $0,50 \pm 0,14$ & - & $0,50 \pm 0,14$ & - \\
\hline BRA003433 & $0,38 \pm 0,18$ & - & $0,54 \pm 0,14$ & - & $0,50 \pm 0,14$ & - \\
\hline BRA014669 & $0,38 \pm 0,18$ & - & $0,30 \pm 0,14$ & - & $0,38 \pm 0,14$ & - \\
\hline BRA014737 & $0,38 \pm 0,18$ & - & $0,54 \pm 0,14$ & - & $0,50 \pm 0,14$ & - \\
\hline BRA014745 & $0,38 \pm 0,18$ & - & $0,29 \pm 0,14$ & - & $0,33 \pm 0,14$ & - \\
\hline BRA014869 & $0,38 \pm 0,18$ & - & $0,37 \pm 0,14$ & - & $0,37 \pm 0,14$ & - \\
\hline BRA014991 & $0,38 \pm 0,18$ & - & $0,54 \pm 0,14$ & - & $0,74 \pm 0,14$ & - \\
\hline BRA0 15156 & $0,33 \pm 0,18$ & - & $0,50 \pm 0,14$ & - & $0,37 \pm 0,14$ & - \\
\hline BRA014664 & $0,33 \pm 0,18$ & - & $0,25 \pm 0,14$ & - & $0,13 \pm 0,14$ & - \\
\hline BRA014711 & $0,13 \pm 0,18$ & - & $0,13 \pm 0,14$ & - & $0,13 \pm 0,14$ & - \\
\hline BRA014788 & $0,00 \pm 0,18$ & - & $0,17 \pm 0,14$ & - & $0,25 \pm 0,14$ & - \\
\hline BRA013714 & $0,00 \pm 0,18$ & - & $0,29 \pm 0,14$ & - & $0,50 \pm 0,14$ & - \\
\hline BRA014770 & $0,00 \pm 0,18$ & - & $0,46 \pm 0,14$ & - & $0,25 \pm 0,14$ & - \\
\hline BRA015113 & $0,00 \pm 0,18$ & - & $0,00 \pm 0,14$ & - & $0,00 \pm 0,14$ & - \\
\hline
\end{tabular}

${ }^{1 / I} \mathrm{I}=2 \mathrm{G} /(\mathrm{G}+\mathrm{P})\left(\mathrm{G}=\mathrm{n}^{\circ}\right.$ de insetos no cultivar avaliado; $\mathrm{P}=\mathrm{n}^{\circ}$ de insetos no cultivar padrão). ${ }^{2 /}$ Classificação dos materiais, onde $(+)=$ mais atrativo que o padrão, $(-)=$ menos atrativo que o padrão e $(N)=$ neutro ou semelhante em relação ao padrão.

BRA014788 que causou a morte de $14 \%$ das ninfas. Embora esses dados sugiram que BRA003531 é o mais adequado às ninfas de primeiro ínstar, uma vez que apresentou baixa mortalidade nessa fase e menor período de tempo na passagem das ninfas para o segundo ínstar, esse quadro, segundo Baldin \& Boiça Jr. (1999), provavelmente deve-se ao fato de as ninfas de primeiro ínstar praticamente não se alimentarem neste estádio, sobrevivendo apenas com as reservas provenientes dos ovos. Esta explicação é a mais viável para este estudo, já que, praticamente todas as ninfas confinadas nos diferentes materiais atingiram o segundo ínstar.
A duração média ou período médio de sobrevivência do segundo ínstar foi maior nos cultivares BRA014664, Exposição, BRA014711 e BRA003531, com $8,42 \pm 0,34,7,70 \pm 0,42,7,10 \pm 0,31$ e $7,00 \pm 0,52$ dias, respectivamente; entretanto, na maioria deles as ninfas não atingiram o terceiro ínstar. Em estudo semelhante, confinando ninfas de $L$. gonagra em frutos e folhas verdes de abóbora, Amaral Filho \& Storti Filho (1976) observaram duração média de 13,88 $\pm 0,30$ dias para o segundo ínstar, ou seja, um período bem superior ao alcançado neste estudo. Praticamente todos os cultivares levaram $100 \%$ das ninfas à morte até o segundo ínstar 
Tabela 2 - Duração média, mortalidade por ínstar e mortalidade total observadas em ninfas de L. gonagra criadas em plântulas de diferentes cultivares de abóbora. Temperatura $=25 \pm 2{ }^{\circ} \mathrm{C}$; U.R. $=65 \pm 10 \%$; Fotofase $=12$ horas.

\begin{tabular}{|c|c|c|c|c|c|c|c|}
\hline \multirow{2}{*}{ Cultivar } & \multicolumn{2}{|c|}{ Primeiro Ínstar (N1) } & \multicolumn{2}{|c|}{ Segundo Ínstar (N2) } & \multicolumn{2}{|c|}{ Terceiro Ínstar (N3) } & \multirow{2}{*}{$\begin{array}{l}\text { Mort. } \\
\text { Total }\end{array}$} \\
\hline & Duração ${ }^{1,2}$ & Mort. & Duração $o^{1,2}$ & Mort. & Duração ${ }^{1}$ & Mort. & \\
\hline & dia & $\%$ & dia & $\%$ & dia & ------- \% & - \\
\hline BRA014711 & $4,26 \pm 0,06 a$ & 0,00 & $7,10 \pm 0,31 a b^{3}$ & 100,00 & - & - & 100,00 \\
\hline BRA014869 & $4,12 \pm 0,05 a b$ & 0,00 & $5,98 \pm 0,19 b^{3}$ & 100,00 & - & - & 100,00 \\
\hline BRA014737 & $4,04 \pm 0,03 a b$ & 0,00 & $5,00 \pm 0,16 \mathrm{~cd}^{3}$ & 100,00 & - & - & 100,00 \\
\hline BRA014664 & $3,96 \pm 0,09 a b c$ & 0,00 & $8,42 \pm 0,34 a^{3}$ & 100,00 & - & - & 100,00 \\
\hline BRA0 14770 & $3,92 \pm 0,04 \mathrm{abcd}$ & 0,00 & $3,58 \pm 0,10 e^{3}$ & 100,00 & - & - & 100,00 \\
\hline BRA003603 & $3,82 \pm 0,05$ bcde & 0,00 & $4,48 \pm 0,21 \mathrm{de}^{3}$ & 100,00 & - & - & 100,00 \\
\hline BRA0 14788 & $3,72 \pm 0,10 \mathrm{cde}$ & 14,00 & $4,24 \pm 0,28 \mathrm{de}^{3}$ & 86,00 & - & - & 100,00 \\
\hline Exposição & $3,64 \pm 0,07 \mathrm{cde}$ & 0,00 & $7,70 \pm 0,42 a b^{3}$ & 100,00 & - & - & 100,00 \\
\hline BRA015113 & $3,62 \pm 0,09 \mathrm{de}$ & 4,00 & $4,38 \pm 0,21 \mathrm{de}^{3}$ & 96,00 & - & - & 100,00 \\
\hline BRA015024 & $3,60 \pm 0,10 \mathrm{e}$ & 2,00 & $3,44 \pm 0,19 e^{3}$ & 98,00 & - & - & 100,00 \\
\hline BRA003531 & $3,12 \pm 0,05 f$ & 4,00 & $7,00 \pm 0,52 \mathrm{ab}$ & 90,00 & $3,00 \pm 0,003^{3}$ & 6,00 & 100,00 \\
\hline $\mathrm{F}$ & $19,85^{*}$ & - & $30,95^{\star}$ & - & - & - & - \\
\hline CV (\%) & 5,92 & - & 18,26 & - & - & - & - \\
\hline
\end{tabular}

${ }^{1 / D a d o s}$ originais; para análise estatística foram transformados em $(x+0,5)^{1 / 2}$.

${ }^{2}$ Médias seguidas de mesma letra não diferem estatisticamente pelo teste de Tukey a $5 \%$.

${ }^{3 / P e r i ́ o d o ~ m e ́ d i o ~ d e ~ s o b r e v i v e ̂ n c i a, ~ u m a ~ v e z ~ q u e ~ t o d a s ~ a s ~ n i n f a s ~ m o r r e r a m ~ a n t e s ~ d e ~ a t i n g i r ~ o ~ i ́ n s t a r ~ s e g u i n t e . ~}$

(exceto BRA003531) indicando a presença de compostos antibióticos em suas plântulas, que impedem que as ninfas completem seu desenvolvimento. Embora 6\% das ninfas confinadas ao cultivar BRA003531 tenham atingido o terceiro ínstar, as plântulas deste material não forneceram nutrientes adequados para que os insetos continuassem se desenvolvendo até a fase adulta, revelando também serem adversas à biologia das ninfas de L. gonagra (Tabela 2). Em estudo semelhante, Caetano \& Boiça Jr. (2000) obtiveram 100\% de mortalidade de ninfas de $L$. gonagra até o segundo ínstar, quando confinadas somente em frutos de cinco espécies de maracujazeiro; entretanto, ao oferecerem também ramos, botões florais e flores, além dos frutos destes materiais, estes autores obtiveram adultos em quatro das espécies testadas.

Devido ao pequeno período de sobrevivência e à elevada mortalidade observada em plântulas de abóbora pode-se inferir que, também nesta cultura, as ninfas de $L$. gonagra necessitam de outras estruturas, além de plântulas, tais como, frutos, botões florais e flores para que se desenvolvam de maneira regular até a fase adulta.

\section{CONCLUSÕES}

O cultivar de abóbora BRA015113 é o menos atrativo aos adultos de $L$. gonagra em relação ao cultivar de moranga Exposição, enquanto que BRA003531 comporta-se como o mais atrativo.

As plântulas de todos os cultivares expressam antibiose sobre as ninfas de L. gonagra, com menor intensidade no cultivar BRA003531, revelando-se como alimentos inadequados para o desenvolvimento das ninfas de L. gonagra.

\section{AGRADECIMENTOS}

À FAPESP, pela Bolsa de Doutorado concedida ao primeiro autor; à CAPES pela Bolsa de Mestrado concedida ao segundo autor, ao CNPq, pela Bolsa de Pesquisa concedida ao terceiro autor e, à Dra. Maria de Fátima Batista (EMBRAPA/CENARGEN) pelo fornecimento das sementes de abóbora.

\section{REFERÊNCIAS BIBLIOGRÁFICAS}

AMARAL FILHO, B.F. do; STORTI FILHO, A. Estudos biológicos sobre Leptoglossus gonagra (Fabricius, 1775), (Coreidae: Hemiptera) em laboratório. Anais da Sociedade Entomológica do Brasil, v.5, p.130-137, 1976.

BALDIN, E.L.L.; BOIÇA JR., A.L. Desenvolvimento de Holhymenia histrio (Fabr.) (Hemiptera: Coreidae) em frutos de cinco cultivares de maracujazeiro (Passiflora spp.) Anais da Sociedade Entomológica do Brasil, v.28, p.421-427, 1999.

BOARETTO, M.A.C.; BRANDÃO, A.L.S.; SÃO JOSÉ, A.R. Pragas do maracujazeiro. In: SÃO JOSÉ, A.R. (Ed.) Maracujá: produção e mercado. Vitória da Conquista: DFZ, UESB, 1994. cap.14, p.99-107.

BOIÇA JR., A.L. Pragas da cultura do maracujazeiro. In: RUGGIERO, C. (Ed.) Maracujá: do plantio à colheita. Jaboticabal: FUNEP, UNESP, 1998. cap.4, p.175-203.

BRAILOVSKY, H.; SÁNCHES, C. Hemiptera-Heteroptera de México XXIX: Revisión de la familia Coreidae Leach; Parte 4. Tribo Anisoscelidini Amyot-Serville. Anales del Instituto de Biologia de la Universidad Nacional Autónoma de México, v.53, p.219-175, 1982. 
CAETANO, A.C.; BOIÇA JR., A.L. Desenvolvimento de Leptoglossus gonagra Fabr. (Hetereoptera: Coreidae) em espécies de maracujazeiro. Anais da Sociedade Entomológica do Brasil, v.29, p.353-359, 2000.

FAO. Production yearbook 1998. Roma, 1999. v.52, p.128.

FNP Consultoria e Comércio. Agrianual 98: Anuário Estatístico da Agricultura Brasileira. São Paulo, 1998. p.428-429.

GALLO, D.; NAKANO, O.; SILVEIRA NETO, S.; CARVALHO, R.P.L.; BATISTA, G.C. de; BERTI FILHO, E.; PARRA, J.R.P.; ZUCCHI, R.A.; ALVES, S.B.; VENDRAMIM, J.D. Manual de entomologia agrícola. 2.ed. São Paulo: Ceres, 1988. 649p.

LARA, F.M. Princípios de resistência de plantas a insetos. 2.ed. São Paulo: Ícone, 1991. 336p.

LIN, H.; KOGAN, M.; FISCHER, D. Induced resistance in soybean to the mexican bean beetle (Coleoptera: Coccinelidae): comparisons of inducing factors. Environmental Entomology, v.19, p.1852-1857, 1990.

LOPES, J.F. Cucurbitáceas. Horticultura Brasileira, v.9, p.9899, 1991.
ROSSETTO, C.J.; NAGAI, V.; IGUE, T.; ROSSETTO, D.; MIRANDA, M.A.C. Preferência de alimentação de adultos de Diabrotica speciosa (Germar) e Cerotoma arcuata (Oliv.) em variedades de soja. Bragantia, v.40, p.179-183, 1981.

RUGGIERO, C.; SÃO JOSÉ, A.R.; VOLPE, C.A.; OLIVEIRA, J. C. de.; DURIGAN, J.F.; BAUMGARTNER, J.G.; SILVA, J.R. da.; NAKAMURA, K.; FERREIRA, M.E.; KAVATI, R.; PEREIRA, V.P. Maracujá para exportação: aspectos técnicos da produção. Brasília: EMBRAPA, SPI, 1996. 64p. (Série Publicações Técnicas. Frupex, 19).

SILVA, A.G.A.; GONÇALVES, C.R.; GALVÃO, D.M.; GONÇALVES, A.J.L.; GOMES, J.; SILVA, M.N.; SIMONI, L. Quarto catálogo dos insetos que vivem nas plantas do Brasil, seus parasitas e predadores. Rio de Janeiro: FIBGE, 1968. t.1, part.2., 622p.

$\overline{\text { Recebido em } 30.10 .00}$ 